antagonists that show close molecular similarity. The crystal structures of unknown pseudo-polymorphic forms of Naltrexone hydrochloride and Naloxone hydrochloride were determined from X-ray powder diffraction data, using the DASH and TOPAS programs [2-3]. With the availability of these newly determined crystal structures and applying hot-humidity stage X-ray powder diffraction in combination with other analytical techniques, a detailed insight into the mechanism of hydrate formation of these narcotic antagonists could be obtained.
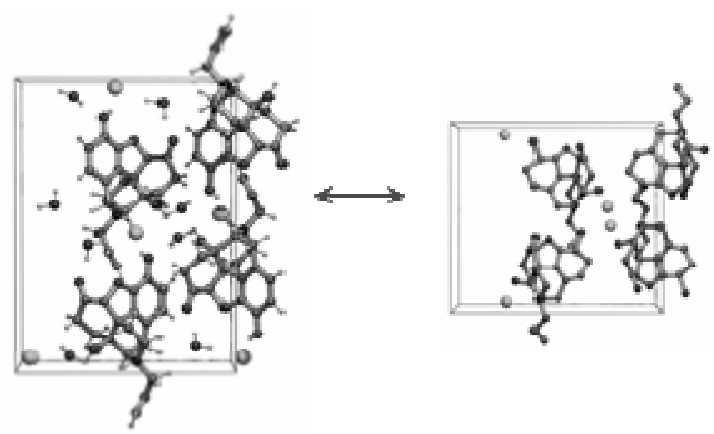

Figure 1. The crystal structure of the Naloxone hydrochloride di-hydrate (left) and anhydrate (right)

[1] Le Dain A.C.; Madsen B.W.; Skelton B.W.; White A.H., Aust.J.Chem., 1992, 45, 635.

[2] David W.I.F.; Shankland K.; Van de Streek J.; Pidcock E.; Motherwell W.D.S.; Cole C.J., J.Appl.Cryst., 2006, 39, 910.

[3] Bruker AXS, TOPAS V2.1: General profile and structure analysis software for powder diffraction data. - User's Manual, 2003, Bruker AXS, Karlsruhe, Germany.

\section{MS31 P04}

X-ray Powder Diffraction Methods in the Investigations of Fibrillar Trimolybdates. Wiesław Łasocha $^{\mathrm{ab}}$, Maciej Grzywa ${ }^{\mathrm{b}}$, Alicja Rafalska-Lasocha ${ }^{\mathrm{a}}$, Bartlomiej Gawel ${ }^{\mathrm{a}}$,

${ }^{\mathrm{a}}$ Faculty of Chemistry Jagiellonian University, ${ }^{\mathrm{b}}$ Institute of Catalysis \& Surface Chemistry PAS, Kraków, POLAND E-mail: lasocha@chemia.uj.edu.pl

\section{Keywords: powder diffractometry, Rietveld refinement powder pattern decomposition, inorganic structure determination}

Due to morphology and a large surface, fibrilar trimolybdates are a very attractive family of compounds, as potential catalysts and ingredients of composite materials. Since fibrillar crystals are too small for single crystal study, their structures are investigated by X-ray powder diffraction techniques, only. Recently, such studies are carried out mainly by direct methods (using EXPO package [1]) or by global optimisation techniques (FOX programme [2]). In our lab we have synthesised more than a dozen of such compounds. First crystal structures of fibrillar trimolybdates were solved, from powder data [3], also in our laboratory. In this report we describe, synthesis and crystal structure determination of a few new trimolybdates. Most of the investigated trimolybdates are built of infinite polymeric $\mathrm{Mo}_{3} \mathrm{O}_{10}{ }^{-2}$ anions and diammonium cations - ${ }^{+} \mathrm{NH}_{3}-\mathrm{R}-\mathrm{N}^{+} \mathrm{H}_{3}$, where $\mathrm{R}$ represents aromatic or aliphatic radical. The studied compounds were synthesised by slow crystallisation from water solution containing $\mathrm{MoO}_{3}$, relevant diamine and water. The obtained solids were thoroughly investigated by analytical, spectroscopic and X-ray methods. In our presentation we are going to describe in details:

- Used for years methods in structure solution of trimolybdates, (emphasising the pitfalls and problems one can come across in the crystallographic investigations).

- Some regularities observed in crystal structures of trimolybdates with organic and inorganic cations.

- Known and potential applications of molybdates.

[1] Altomare A, Burla M, Camalli M. Carrozzini B. Cascarano G, Giacovazzo C, Guagliardi,A. Moliterni,G.;Polidori G. Rizzi R.J., Appl. Cryst. 32 (1999) 339-340.

[2] V. Favre-Nicolin V, Cerny R, J. Appl. Cryst. 35 (2002) 734

[3] Lasocha W, Jansen J, Schenk H,. J. Solid State Chem., 109, 1-4 (1994)

MS31 P05

Study of Anatase to Rutile Phase Transition in Titanium Dioxide $\left(\mathrm{TiO}_{2}\right)$ thin films by sol-gel dipcoating method Raouf Mechiakh, Rabah Bensaha, Ceramics Laboratory, University Mentouri of Constantine, Algeria.

E-mail : raouf_mechiakh@yahoo.frbensaha@yahoo.fr

Keywords: $\mathrm{TiO}_{2}$, sol-gel, anatase.

Titania films are one of the hotly investigated transition metal oxide thin films lately, due to the wide and versatile range of application possibilities these films offer. The domains of application touched by this material are optical filters, optical waveguides, chemical sensors, solar cells, thin film capacitors, electrochromic materials and more [1-3]. Titanium dioxide thin films have been prepared from tetrabutyl-orthotitanate solution and buthanol as a solvent by sol gel dip-coating technique [4-6]. The deposits are carried out on sapphire (mono-crystalline) substrates, annealed between 600 to $1400^{\circ} \mathrm{C}$. Structural and optical properties of $\mathrm{TiO}_{2}$ thin films prepared using a sol-gel process have been examined at different treatment temperatures and for different layer counts (number of dippings). The morphology, surface structure and composition of the films were investigated by X-ray Diffraction (XRD), Raman Spectroscopy, Scanning electron microscopy (SEM), Optical Microscopy, Infrared and Ultraviolet spectroscopy. The as-deposited $\mathrm{TiO}_{2}$ thin films crystallize in anatase phase between 600 and $800^{\circ} \mathrm{C}$, and into the anatase-rutile phase at $1000^{\circ} \mathrm{C}$, and further into the rutile phase at $1200^{\circ} \mathrm{C}$. It was found that the film consisted of titanium dioxide nanocrystals. The nanocrystals size of $\mathrm{TiO}_{2}$ thin films is increased with increasing treatment temperature.

[1] Bennett J.M; Pelletier E; Albrand G; Appl. Opt. 1989, 28, 3303.

[2] Desu S.B; Mater. Sci. Eng. 1992, B 13, 299.

[3] Gratzel M; Comment. Inorg. Chem. 1991, 12, 93.

[4] Mechiakh R; Bensaha R; M. J. Condensed Mater. 2006, 7, 54.

[5] Mechiakh R; Bensaha R; C. R. Physique. 2006, 7, 464.

[6] Mechiakh R; Meriche F; Kremer R; Bensaha R; Boudine B;

Boudrioua A; JNOG, Chambéry, France. 2005, 258 